\title{
Influence of flange on the shear capacity of reinforced concrete beams
}

\author{
Kaiss Sarsam ${ }^{1, *}$, Raid Khalel $^{1}$ and Nisreen Mohammed $^{1}$ \\ ${ }^{1}$ Building and Construction Engineering Department, University of Technology, Baghdad-Iraq
}

\begin{abstract}
In structural engineering ( $\mathrm{RC}$, steel, etc.) it is usual to base the shear strength of members on the web only- e.g. in RC the stirrups used are usually called "web reinforcement". Presently all codes, and several researches, base the strength of members on the capacity of the web alone. 93 tests of T-beams failing in shear available from the literature are studied in this work to estimate the influence of flanges on the shear capacity of RC beams. These include 32 ones without web reinforcement and 61 with stirrups. Comparison between test results and theoretical shear capacity show that all available equations conservatively estimate the occurrence of shear failure. In this work an equation for predicting the contribution of the flange to shear capacity in T-beams is presented.

The best available design method obtained from the literature leads to a coefficient of variation (COV) of $17.58 \%$ compared to $13.46 \%$ for the proposed design method in this work.
\end{abstract}

\section{Introduction}

There are significantly different methods to estimate shear capacity of reinforced concrete (RC) beams. The main parameters affecting the occurrence of shear failure are: concrete compressive strength, longitudinal reinforcement ratio, shear span to effective depth ratio, and size effect of the member. Bresler and MacGregor [1] indicate that shear failure is commonly initiated by the occurrence of diagonal cracks developing in the shear span, and that the flexural cracks always come before the occurrence of diagonal cracks in rectangular, I, and T- sections. They noted that the shape of the beam (I and T-sections) influences the shear capacity and the behavior including propagation of diagonal cracking due to the different magnitudes of shearing stress developed in the web. However, not much attention has been given to the behavior of RC beams with $\mathrm{T}$-sections.

Swamy and Qureshi [2] proposed a procedure to estimate the ultimate shear strength of the compression zone of T-beams. This procedure was derived by using the concept of biaxial stress criterion and was based on Mohr's theory of failure. However, this method needs several steps of calculation and is difficult to apply in practice.

Ahmed [3] proposed an empirical equation which is simpler than the procedure of reference 2 . This equation includes the flange contribution in predicting the ultimate shear capacity of T-sections.

Existing equations for shear capacity of concrete available in the codes do not take into account the influence of the flange in T-sections $[4,5]$.

In this work, empirical equations of researchers and design codes for shear capacity of beams are compared with test results obtained from the literature to find an equation for predicting the contribution of flange to the shear capacity of concrete in RC beams with $\mathrm{T}$-sections.

\section{Research significance}

Several code and research estimates of shear capacity of $\mathrm{RC}$ beams are studied in this work. A data base of 93 tests is used in this work: 32 without stirrups and 61 with stirrups. It is found that including of flange contribution leads to a significantly improved COV for all available 93 tests from the literature. In fact, the proposed equation leads to a COV of $13.46 \%$ compared to the range of $(17.58 \%-42.55 \%)$ for the available methods.

\section{Experimental investigations}

The 93 shear tests have been taken from the literature: Taub and Neville [6]; Swamy and Qureshi [7]; Haddadin et al [8]; Placas and Regan [9]; Palaskas et al [10]; Kotsovos et al [11]; and Thamrin et al [12].

All of these RC T- beams involved slender ones (shear span /effective depth ratio $\geq 2.5$ ) that failed in shear under concentrated loading. Table 1 indicates the range of variables in all 93 tests.

Table 1. Range of variables

\begin{tabular}{|c|c|c|}
\hline Variable & Unit & Range \\
\hline$f_{c}^{\prime}$ & $\mathrm{MPa}$ & $11.99-56.95$ \\
\hline$a / d$ & ---- & $2.5-10.4$ \\
\hline$\rho_{w}$ & ---- & $0.49 \%-5.2 \%$ \\
\hline$\rho_{v} f_{y t}$ & $\mathrm{MPa}$ & $0-2.71$ \\
\hline$b_{w} d$ & $\mathrm{~mm}^{2}$ & $2903-76000$ \\
\hline$b / b_{w}$ & ---- & $2-7$ \\
\hline
\end{tabular}

\footnotetext{
* Corresponding author: kaisssarsam $@$,yahoo.com
} 
where:

$f_{c}^{\prime}=$ cylinder compressive strength of concrete, $\mathrm{MPa}$

$a=$ shear span, equal to the distance from center of concentrated load to center of support for simply supported members, $\mathrm{mm}$

$d=$ distance from extreme compression fiber to centroid of longitudinal tension reinforcement, $\mathrm{mm}$

$\rho_{w}=$ ratio of $A_{s}$ to $b_{w} d$

$A_{S}=$ area of non prestressed longitudinal tension reinforcement, $\mathrm{mm}^{2}$.

$b_{w}=$ web width, $\mathrm{mm}$

$\rho_{v}=$ ratio of $A_{v}$ to $b_{w} S$

$A_{v}=$ area of shear reinforcement within spacing $\mathrm{S}, \mathrm{mm}^{2}$

$S=$ center- to- center spacing of transverse reinforcement, $\mathrm{mm}$

$f_{y t}=$ specified yield strength of transverse reinforcement, $\mathrm{MPa}$.

$b=$ flange width, $\mathrm{mm}$

\section{Code estimates of RC beam shear capacity}

\subsection{BS 8110:1997 [13]}

$=0.79\left(\frac{100 A_{s}}{b_{w} d}\right)^{1 / 3}\left(\frac{400}{d}\right)^{1 / 4}\left(\frac{f_{c u}}{25}\right)^{1 / 3} b_{w} \cdot d / \gamma_{m}$

$+\frac{0.95 A_{v} f_{y t} d}{S}$

$$
\begin{gathered}
0.15 \leq \frac{100 A_{s}}{b_{w} d} \leq 3.0 \\
\frac{400}{d} \geq 1.0
\end{gathered}
$$

where:

$V_{r B S}=$ estimated shear strength per reference $13, \mathrm{~N}$ $\left(\frac{400}{d}\right)=$ size effect, used for enhancement only

$f_{c u}=$ cube compressive strength of concrete, not to exceed $40 \mathrm{MPa}$. For comparison in this work, $\gamma_{m}=1.25$

\subsection{Australian Code; AS 3600:2001 [14]}

$$
\begin{aligned}
& V_{r A S}=0.7\left[\beta_{1} b_{w} d\left(\frac{A_{s} f_{c}^{\prime}}{b_{w} d}\right)^{1 / 3}+\frac{A_{v} f_{y t} d}{S}\right] \\
& \beta_{1}=1.1\left(1.6-\frac{d}{1000}\right) \geq 1.1 \quad[\text { size effect }]
\end{aligned}
$$

where:

$V_{r A S}=$ estimated shear strength per reference $14, \mathrm{~N}$

\subsection{Canadian code; A23.3:2004 [15]}

$$
\begin{array}{r}
V_{r C A N}= \\
0.65 \beta \sqrt{f_{c}^{\prime}} b_{w} d_{v}+\frac{0.85 A_{v} f_{y t} d_{v} \cot 35^{o}}{s}
\end{array}
$$

$\beta=0.18$, with stirrups

$$
\beta=\frac{230}{1000+d_{v}}, \text { without stirrups }
$$

$\leq 64 M P a$, upper limit

$$
d_{v}=\begin{gathered}
0.9 d \\
0.72 h
\end{gathered} \mid \text { whichever is greater }
$$

where:

$V_{r C A N}=$ estimated shear strength per reference $15, \mathrm{~N}$

$h=$ overall thickness or height of member, $\mathrm{mm}$

\subsection{Euro code: 2014 [16]}

$$
\begin{array}{r}
V_{r E U R O}=\left[0.12 k\left(100 \rho_{w} f_{c}^{\prime}\right)^{1 / 3}\right] b_{w} d \\
+\frac{0.75 A_{v} f_{y t} d}{S}
\end{array}
$$

where:

$V_{\text {rEURO }}=$ estimated shear strength per reference $16, \mathrm{~N}$

$$
k=1.0+\sqrt{200 / d} \leq 2.0
$$

\subsection{ACI 318M-14 [17]- Simplified method}

$$
\begin{gathered}
V_{\text {rACI-S }}=0.75\left[0.17 \sqrt{f_{c}^{\prime}} b_{w} d\right. \\
\left.+\frac{A_{v} f_{y t} d}{S}\right]
\end{gathered}
$$

where:

$V_{\text {rACI-S }}=$ estimated shear strength per reference 17; based on simplified ACI method, $\mathrm{N}$

\subsection{ACI 318M-14 [17]- Detailed method}

$$
\begin{gathered}
V_{r A C I-D}=0.75\left[\left(0.16 \sqrt{f_{c}^{\prime}}+17 \rho_{w} \frac{V_{u} d}{M_{u}}\right) b_{w} d\right. \\
\left.+\frac{A_{v} f_{y t} d}{S}\right] \\
\frac{V_{u} d}{M_{u}} \leq 1
\end{gathered}
$$

where:

$V_{r A C I-D}=$ estimated shear strength per reference 17 ; based on detailed ACI method, $\mathrm{N}$

$V_{u}=$ factored shear force at section, $\mathrm{N}$

$M_{u}=$ factored moment at section, N.mm 
$V_{r S \& A}=$ estimated shear strength per reference $20, \mathrm{~N}$

\section{Existing research estimates of RC beam shear capacity}

\subsection{Zsutty approach [18]}

$$
V_{\text {rzsutty }}=2.17\left(\rho_{w} f_{c}^{\prime} \frac{d}{a}\right)^{1 / 3} b_{w} d+\frac{0.75 A_{v} f_{y t} d}{S}
$$

where:

$V_{\text {rZsutty }}=$ estimated shear strength per reference $18, \mathrm{~N}$

\subsection{Niwa et al approach [19]}

$$
V_{\text {rNIWA }}
$$

$=0.2\left(\rho_{w} f_{c}^{\prime}\right)^{1 / 3}(d)^{1 / 4}\left(0.75+1.4 \frac{d}{a}\right) b_{w} d$

$+\frac{0.75 A_{v} f_{y t} d}{S}$

where:

$V_{\text {rNIWA }}=$ estimated shear strength per reference $19, \mathrm{~N}$

\subsection{Sarsam and Al-Musawi approach [20]}

$$
\begin{gathered}
V_{r S \& A}=1.8\left(f_{c}^{\prime} \rho_{w} \frac{V_{u} d}{M_{u}}\right)^{0.38} b_{w} d \\
+\frac{A_{v} f_{y t} d}{S} \\
\frac{V_{u} d}{M_{u}} \leq 0.5
\end{gathered}
$$

where:

\subsection{Kuo et al approach [21]}

$$
\begin{gathered}
V_{\text {rKUO }}=1.17\left(\frac{a}{d}\right)^{-0.7} \sqrt{f_{c}^{\prime}} b_{w} C \\
+A_{v} f_{y t}\left(\frac{d}{S}-1\right) \\
\frac{C}{d}=\sqrt{2 \rho_{w} n+\left(\rho_{w} n\right)^{2}}-\rho_{w} n \\
n=\frac{E_{S}}{E_{C}} \\
E_{C}=4700 \sqrt{f_{c}^{\prime}}
\end{gathered}
$$

where:

$V_{\text {rKUO }}=$ estimated shear strength per reference $21, \mathrm{~N}$ $E_{S}=$ modulus of elasticity of reinforcement $=200000$ $\mathrm{MPa}$

$E_{c}=$ modulus of elasticity of concrete, $\mathrm{MPa}$

\section{Results and discussion}

From the methods used in codes \& research proposals, a comparison was made for the ratio of $\left(V_{\text {exp }} / V_{r}\right)$, where:

$V_{\text {exp }}=$ Shear resistance of tested beam, $\mathrm{N}$

$V_{r}=$ calculated shear resistance based on different methods of prediction, $\mathrm{N}$

Table 2 gives a comparison of the results of the different methods, based on the ratio of $\left(V_{\text {exp }} / V_{r}\right)$.

Table 2. Comparison of the ratio of $\left(V_{\text {exp }} / V_{r}\right)$ for all 93 beam tests

\begin{tabular}{|c|c|c|c|c|c|c|c|c|c|c|c|}
\hline Detail & BS [13] & $\begin{array}{c}\text { Australian } \\
\text { code [14] }\end{array}$ & $\begin{array}{c}\text { Canadian } \\
\text { code [15] }\end{array}$ & $\begin{array}{c}\text { Euro } \\
\text { code [16] }\end{array}$ & $\begin{array}{c}\text { ACI [17]- } \\
\text { simplified }\end{array}$ & $\begin{array}{c}\text { ACI [17]- } \\
\text { detailed }\end{array}$ & $\begin{array}{c}\text { Zsutty } \\
\text { approach } \\
{[18]}\end{array}$ & $\begin{array}{c}\text { Niwa } \\
\text { approach } \\
{[19]}\end{array}$ & $\begin{array}{c}\text { Sarsam and } \\
\text { Al-Musawi } \\
{[20]}\end{array}$ & $\begin{array}{c}\text { Kou et al } \\
{[21]}\end{array}$ & $\begin{array}{c}\text { Proposed } \\
\text { method }\end{array}$ \\
\hline $\begin{array}{c}\text { Equation } \\
\text { used }\end{array}$ & $(1)$ & $(4)$ & $(6)$ & $(11)$ & $(13)$ & $(14)$ & $(16)$ & $(17)$ & $(18)$ & $(20)$ & $(24)$ \\
\hline Mean & 1.808 & 2.079 & 2.634 & 2.433 & 2.619 & 2.418 & 1.903 & 2.894 & 1.808 & 1.832 & 1.718 \\
\hline $\begin{array}{c}\text { Standard } \\
\text { deviation }\end{array}$ & 0.34739 & 0.36546 & 1.12085 & 0.94413 & 0.88921 & 0.69026 & 0.66996 & 1.21593 & 0.32701 & 0.32303 & 0.23112 \\
\hline COV \% & 19.215 & 17.580 & 42.547 & 38.797 & 33.957 & 28.545 & 35.203 & 42.021 & 18.088 & 17.636 & 13.464 \\
\hline Max. ratio & 2.669 & 3.066 & 6.063 & 5.354 & 5.341 & 4.608 & 4.002 & 6.194 & 2.970 & 2.724 & 2.348 \\
\hline Min. ratio & 1.131 & 1.184 & 1.246 & 1.164 & 1.148 & 1.166 & 0.889 & 1.241 & 1.213 & 1.033 & 1.130 \\
\hline $\begin{array}{c}\text { Range } \\
\text { max/min) }\end{array}$ & 2.360 & 2.588 & 4.864 & 4.190 & 4.652 & 3.953 & 3.113 & 4.953 & 2.449 & 2.637 & 2.078 \\
\hline $\begin{array}{c}\text { Number } \\
<1\end{array}$ & 0 & 0 & 0 & 0 & 0 & 0 & 1 & 0 & 0 & 0 & 0 \\
\hline
\end{tabular}

* Number $<1$ indicates the number of specimens (out of 93) for which $V_{\exp }<V_{r}$.

Regression analysis was performed on all 93 tests. This led to the following equation:

$$
\begin{gathered}
V_{r, \text { PROP. }}=1.7\left(f_{c}^{\prime} \rho_{w} \frac{V_{u} d}{M_{u}}\right)^{0.5} \alpha+\frac{\phi_{S} A_{v} f_{y t} d}{S} \\
\frac{V_{u} d}{M_{u}} \leq 0.5 \\
\alpha=b_{w} d+0.7\left(b-b_{w}\right) h_{f}
\end{gathered}
$$


where:

$V_{r, P R O P .}=$ estimated shear strength by the proposed equation, $\mathrm{N}$

$\alpha=$ parameter taking into account the effect of flange in $\mathrm{T}$-section.

$\phi_{S}=0.8$

As can be seen in Eq. (26), the contribution of flange to shear capacity will be eliminated in the case of beams with rectangular cross section $\left(h_{f}=0\right)$.

The last column in Table 2 indicates the various ratios of $\left(V_{\text {exp }} / V_{r}\right)$ for the proposed method_- Eq. (24). In this table, the COV values range between $(17.58 \%$ $42.55 \%$ ). By using the proposed equation, the COV value decreases to $13.46 \%$.

Figs. 1-5 indicate the trend of the influence of major parameters on the prediction of shear resistance of 4 methods: BS [13], ACI [17] - detailed method, reference 20 , and the proposed method. Fig. 1 is plotted in order to examine the effect of wide variation of $f_{c}^{\prime}$ on the shear capacity of T-sections. This Fig. shows that the proposed method reveals little change, despite the change in $f_{c}^{\prime}$ between $(11.99-56.95) \mathrm{MPa}$. This contrasts with other methods- e.g. the ACI [17] method leads to significantly uneconomic prediction of strength with rising $f_{c}^{\prime}$. Fig. 2 also shows little change in prediction for the proposed method with a/d between (2.5-10.4). Again, the other methods lead to dropping values of the ratios of $\left(V_{\text {exp }} / V_{r}\right)$, with the highest in the ACI [17] method.

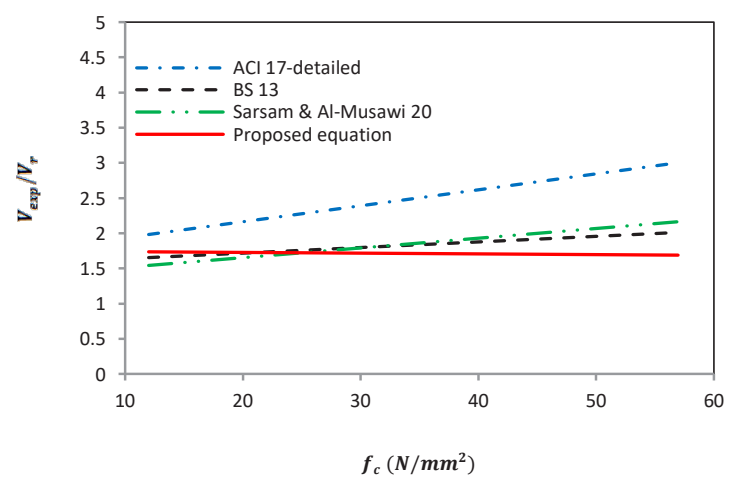

Fig. 1. Influence of $f_{c}^{\prime}$ on the ratio $V_{\exp } / V_{r}$

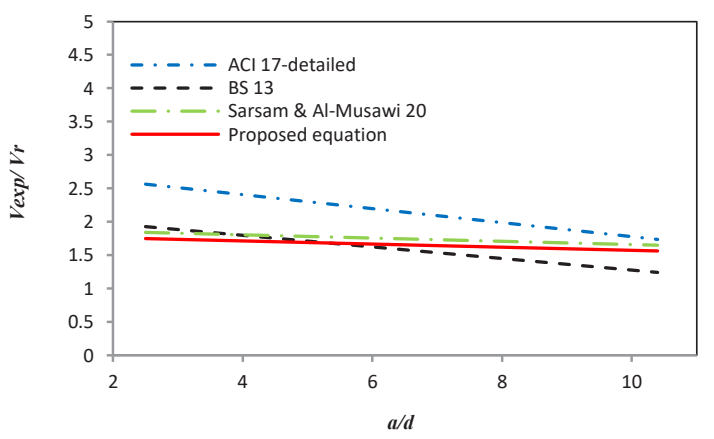

Fig. 2. Influence of $a / d$ on the ratio $V_{\exp } / V_{r}$

While Fig. 3 illustrates little change in prediction for the proposed method with $\rho_{w}(0.49 \%-5.2 \%)$, this is not the case with other methods- especially the ACI [17] method. Similar results are shown in Fig. 4 with significant influence of $\rho_{v} f_{y t}$ ranging between 0 (without stirrups) - 2.71 MPa. The proposed method shows no trend of $\rho_{v} f_{y t}$ influence, contrasting with the other methods when the safety factor decreases with rising $\rho_{v} f_{y t}$. In Fig. 5 , the influence of $b / b_{w}$ ranging between (2-7) on the shear capacity prediction was examined. All the methods show a decrease in the factor of safety with rising $b / b_{w}$ - especially the ACI [17] method.

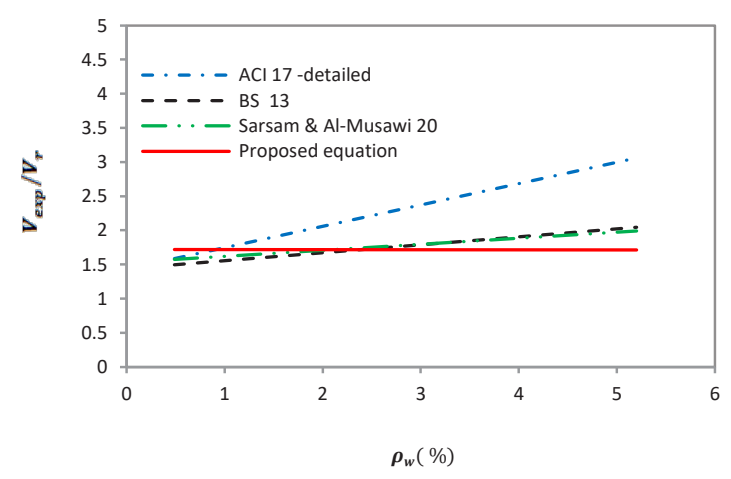

Fig. 3. Influence of $\rho_{\mathrm{w}}$ on the ratio $\mathrm{V}_{\mathrm{exp}} / \mathrm{V}_{\mathrm{r}}$

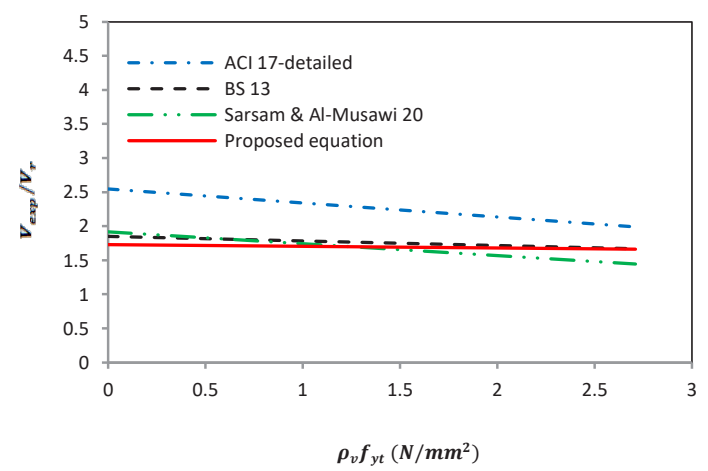

Fig. 4. Influence of $\rho_{\mathrm{v}} f_{\mathrm{yt}}$ on the ratio $\mathrm{V}_{\mathrm{exp}} / \mathrm{V}_{\mathrm{r}}$

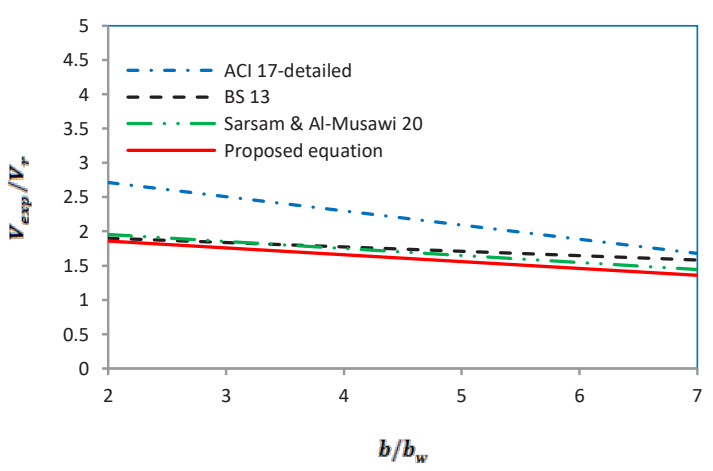

Fig. 5. Influence of $b / b_{w}$ on the ratio $V_{\text {exp }} / V_{r}$ 


\section{Conclusions}

Based on 93 tests of $\mathrm{RC} \mathrm{T}$ - beams failing in shear obtained from the literature, the following conclusions are made:

1- Regression analysis of all tests indicates that the ratio of $\left(V_{\text {exp }} / V_{r}\right)$ drops significantly to $13.46 \%$ for the proposed method (which is taking into account the contribution of flange on shear capacity), compared with the COV values of the other methods $(17.58 \%-42.55 \%)$.

2- The Australian Code [14] Method gives the lowest COV of all existing methods- $17.58 \%$. It is clear from the proposed method that using $\alpha$ Eq. (26) for flange effect has significantly improved the COV for shear capacity prediction.

3- The proposed method by Kuo et al [21] also leads to a significant drop in COV compared to several code methods. In contrast with this method, the proposed method leads to a much simpler prediction of shear strength.

4- Of the code methods, the Canadian Code [15] Method gives the highest COV of $42.55 \%$. This is because strength is based only on $\left(f_{c}^{\prime}\right)^{1 / 2}$. However, with $\left(f_{c}^{\prime}\right)^{1 / 2}$ in the ACI [17], the $\mathrm{COV}$ is lower with the simplified method at $33.96 \%$.

5- All the empirical equations used to calculate shear strength conservatively predict the shear capacity of the beams. The proposed method also leads to a conservative prediction for $\mathrm{T}$ beams.

6- In contrast with the proposed method, Figs. 1 and 3 show significant safety factor changes, respectively with increasing $f_{c}^{\prime}$ and $\rho_{w}$ by BS [13], ACI [17], and reference 20.

7- With the proposed design method- Eq. (24), Figs. 1-4 show little change in safety factor with increasing $f_{c}^{\prime}, a / d, \rho_{w}$, and $\rho_{v} f_{y t}$

8- In all design methods, there is a decrease in safety factor with increasing $b / b_{w}-$ Fig. 5 .

\section{Acknowledgment}

This work was carried out at the Building and Construction Engineering Department, University of Technology, Baghdad, Iraq. The authors express their gratitude to the department.

\section{References}

1. B. Bresler, J. MacGregor, ASCE Journal, 93, ST1, 343-372 (1967)

2. R. Swamy, S. Qureshi, Materiaux et Construction 7, 39, 181-189 (1974)
3. A. Ahmed, M.Sc. thesis, University of Technology, Baghdad, Iraq, 87 pp. (2001)

4. P. Zararis, ACI Structural Journal 103, 5, 693-700 (2006)

5. A. Tureyen, T. Wolf, R. Frosch, ACI Structural Journal 103, 5, 656-663 (2006)

6. J. Taub, A. Neville, ACI Journal 57, 8, 193-220 (1960)

7. R. Swamy, S. Qureshi, Strength, Cracking, and Deformation Similitude in Reinforced T-Beams Under Bending and Shear, ACI Journal Proceedings 68, 3, 187-195 (Mar. 1971)

8. M. Haddadin, S. Hong, A. Mattock, Stirrup Effectiveness in Reinforced Concrete Beams with Axial Force, ASCE Proceedings 97, ST9, 22772297 (Sep. 1971)

9. A. Placas, P. Regan, Shear Failure of Reinforced Concrete Beams, ACI Journal Proceedings 68, 10, 763-773 (Oct. 1971)

10. M. Palaskas, E. Attiogbe, D. Darwin, ACI Journal 78, 6, 447-455 (1981)

11. M. Kotsovos, J. Bobrowski, J. Eibi, The Structural Engineer 65, B (1), 1-10 (1987)

12. R. Thamrin, J. Tanjung, R. Arianti, O.F. Nur, A. Devinus, Journal of Engineering Science and Technology, Andalas Universiy, Indonesia, 1-15 (2014)

13. BS 8110: (1997), Structural Use of Concrete, Part 1- Code of Practice for Design and Construction, British Standards Institution, London, UK, 168 pp. (1997)

14. AS 3600- (2001), Concrete Structures, Standards Australia International, Sydney, Australia, 175 pp. (2001)

15. A23.3-04, Design of Concrete Structures, Canadian Standards Association, CSA Standard, Ontario, Canada, 214 pp. (2004)

16. British Standards Institution, Eurocode 2: Design of Concrete Structures, Part 1-1: General Rules and Rules for Buildings, BSI, London, UK, (2014)

17. ACI Committee 318, Building Code Requirements for Structural Concrete (ACI 318M-14) and Commentary (ACI 318RM-14), American Concrete Institute, Farmington Hills, Michigan, 519 pp. (2014)

18. T. Zsutty, ACI Journal, 65, 11, 942-951 (1968)

19. J. Niwa, K. Yamada, K. Yokozawa, H. Okamura, Concrete Library International of JSCE, 9, 65-84 (1987)

20. K. Sarsam, J. Al-Musawi, ACI Structural Journal, 89, 6, 658-664 (1992)

21. W. Kuo, T. Hsu, S. Hwang, ACI Structural Journal, 111, 4, 809-818 (2014) 